\title{
Hexachlorobenzene and octachlorostyrene in plasma of aluminium foundry workers using hexachloroethane for degassing
}

\author{
Anders I Seldén, Yvonne Nygren, Håkan B Westberg, Lennart S Bodin
}

Departments of Occupational and Environmental Medicine, Örebro Medical Centre Hospital, Örebro, and Faculty of Health Sciences, Linköping University, Linköping, Sweden

A I Seldén

H B Westberg

Department of NBC Defence, National Defence Research Establishment, Umeå, Sweden

Y Nygren

Department of Occupational and Environmental Medicine, Örebro Medical Centre Hospital, Örebro, Sweden

L S Bodin

Correspondence to: Dr A Seldén, Department of Occupational and Environmental Medicine, Örebro Medical Centre Hospital, SE-701 85 Örebro, Sweden.

Accepted 26 February 1997

\begin{abstract}
Objectives-To study the load of selected organochlorine compounds in the blood of aluminium foundry workers who use hexachloroethane as a degassing agent for aluminium and to measure some possible effects on internal organs.

Methods-Plasma from nine male aluminium foundry workers with past experience of use of hexachloroethane and 18 controls (two controls per exposed case) matched for residence, sex, age, and socioeconomic status was analysed for hexachlorobenzene (HCB), (P-HCB), and octachlorostyrene (P-OCS) with low resolution gas chromatography-mass spectrometry. Serum samples from the same subjects were analysed for standard kidney, pancreas, and liver function variables. Analysis of variance (ANOVA) with the triplets retained, a non-parametric test, and linear regression were used for the analysis.
\end{abstract}

Results-A fourfold increase of mean P-HCB was found among the exposed subjects compared with the controls (313.1 v 66.9 ng/g lipid; $P<0.01$; (ANOVA model)). For P-OCS this difference was even larger (54.6 $v 0.7 \mathrm{ng} / \mathrm{g}$ lipid; $P<0.01)$. Results were still significant $(P<0.05)$ with non-parametric testing. Within the exposed group there was a good correlation between the In P-HCB $(r=0.80)$ and In P-OCS $(r=0.91)$, respectively, with the cumulative number of years of exposure to hexachloroethane. No significant difference in kidney, pancreas, or liver function was found between the two groups.

Conclusions-Aluminium degassing with hexachloroethane may increase the body burden of selected organochlorine compounds as reflected by HCB and OCS measurements. With the inherent limitations of this investigation no signs of subclinical organ toxicity were found.

(Occup Environ Med 1997;54:613-618)

Keywords: aluminium foundry workers; hexachloroethane; hexachlorobenzene; octachlorostyrene; biological monitoring; liver enzymes

Hydrogen gas derived from ambient water vapour is easily dissolved in molten aluminium causing porosities and impaired mechanical properties in aluminium castings. Hydrogen degassing is therefore often necessary to improve the quality of the melt. Introduction of a gas free from hydrogen and water, particularly nitrogen or chlorine, into the molten aluminium removes most of the hydrogen by diffusion into the sparging gas bubbles. ${ }^{12}$ Since the late 1930s hexachloroethane has been used as an inexpensive and simple means of introducing chlorine gas by plunging the chemical in tablets or as a crystalline powder to the bottom of the melt. This operation has been considered an efficient and safe way of aluminium degassing ${ }^{3}$ but considerable amounts of irritating fume are produced. ${ }^{14}$

Early studies of the contents of the fumes from hexachloroethane based aluminium degassing gave no reasons for serious concern and besides aluminium chloride and hydrochloric acid only minor emissions of chlorine gas and phosgene were found. ${ }^{15}$ More recent work, however, indicates that this technology invokes more complex reactions including the formation of higher organochlorine compounds, hexachlorobenzene (HCB) and octachlorostyrene (OCS) in particular, ${ }^{6-8}$ with a yield of 4.3 $5.0 \mathrm{~kg}$ HCB per metric tonne of hexachloroethane used. For OCS the corresponding figure is about $0.8 \mathrm{~kg}$ per tonne hexachloroethane. ${ }^{8}$ Polychlorinated dioxins and dibensofurans have also been found in the emissions but at considerably lower concentrations. ${ }^{8}$ Hexachlorobenzene and OCS are chemically and toxicologically closely related substances capable of inducing hepatic porphyria in experimental animals ${ }^{9-12}$; HCB also in humans. ${ }^{13-15}$ Moreover, HCB is an experimental carcinogen and possibly also carcinogenic in humans although the epidemiological evidence is weak. ${ }^{16}$ However, a case of hepatocellular carcinoma in a foundry worker exposed to the fumes of hexachloroethane based aluminium degassing has been described. ${ }^{18}$ Recently, a cluster of thyroid neoplasms, soft tissue sarcoma, and brain neoplasms in male inhabitants of a Spanish village was associated with environmental contamination of $\mathrm{HCB}$ and other organochlorine compounds emitted from a neighbouring factory producing chlorinated solvents. ${ }^{19}$

The discovery in the 1980 s of HCB in the emissions from hexachloroethane based aluminium degassing stimulated prompt actions from the Swedish industry involved, and at the time of the present study this chemical had been withdrawn from the domestic market for some time. However, hexachloroethane is still 
being used elsewhere-for example, in the United Kingdom ${ }^{20}$ - and because of the potentially serious long-term health effects of this degassing technique a pilot monitoring study of HCB and OCS in the blood of workers previously exposed was still considered appropriate. The results are reported here.

\section{Material and methods}

Nine male smelter workers from six aluminium foundries (five sand casting and one gravity die casting foundry) in central and south eastern Sweden were invited to participate in the study, which took place in 1992. The workers were selected by the local management on the basis of their previous experience with hexachloroethane-that is, they had been directly involved in the degassing procedure. For each exposed case two local controls matched for sex, age ( \pm 5 years $)$, and socioeconomic status (blue collar workers) were also selected, normally by the local occupational health nurse. With two exceptions the controls were employed at the same company as the cases but they worked in buildings separated from the smelter department with which they had only occasional contact.

Informed consent was obtained from the nine cases (median (range) age 50 (26-64)) and the 18 controls (51 (28-62)) who responded to a set of standardised, self administered questionnaires on work history, previous and present health, and smoking habits. ${ }^{21}$ The questionnaires were checked and completed, if necessary. The subjects were examined clinically by one of us (AS), and blood plasma and serum samples were obtained by venepuncture. The plasma samples were coded, frozen, and stored at $-20^{\circ} \mathrm{C}$ before the analysis of organochlorine compounds one year later, whereas the serum samples were analysed the next day at the Department of Clinical Chemistry, s:t Göran's Hospital, Stockholm for standard liver function variables (bilirubin, alcaline phosphatase, alanine amino transferase, aspartate amino transferase, $\gamma$-glutamyl transferase, as well as $\alpha$-amylase, creatinine, and lactate dehydrogenase).

The proportion of current and former smokers (stopped smoking at least six months before investigation) was $67 \%$ and $11 \%$ respectively, among the exposed subjects versus $22 \%$ and $28 \%$ among the controls.

The study was approved by the medical research ethics committee at Örebro County Council (decision No 182/92).

PLASMA ANALYSIS OF HCB AND OCS Five $\mathrm{ml}$ of plasma were pipetted into a Teflon centrifuge tube to which $2.5 \mathrm{ml}$ of methanol was added, and the tube was vortexed for 15 seconds. The denatured plasma was extracted with $6.25 \mathrm{ml} \mathrm{n}$-hexane/diethyl ether $1: 1(\mathrm{v} / \mathrm{v})$ by agitation for 10 minutes. The tube was centrifuged for five minutes at $3000 \mathrm{rpm}$ and the organic layer was transferred to a tarred glass container. The extraction procedure was repeated twice and the combined organic extract was evaporated to dryness.
The fat residue was separated gravimetrically and then resolved in $1 \mathrm{ml} \mathrm{n}$-hexane. The solute was put on a $10 \mathrm{~mm}$ internal diameter glass column with a $50 \mathrm{ml}$ reservoir packed with $10 \mathrm{~mm}$ anhydrous sodium sulphate, $1 \mathrm{~g}$ neutral silica gel, $4 \mathrm{~g}$ sulphuric acid impregnated silica gel, $2 \mathrm{~g}$ basic silica gel, and $10 \mathrm{~mm}$ anhydrous sodium sulphate. The column was eluted with $60 \mathrm{ml} \mathrm{20 \%}$ methylene chloride in $\mathrm{n}$-hexane. The eluant was collected and evaporated to about $1 \mathrm{ml}$ and caution was taken to prevent the extract from going to dryness. One nanogram ${ }^{13} \mathrm{C}_{12}$-PCB IUPAC no 101 was added as external standard and $30 \mu \mathrm{l}$ of tetradecane was added as keeper solution. A gentle stream of nitrogen was applied to concentrate the sample just to dryness. A $1 \mu$ l sample was analysed on a Hewlett Packard5890 gas chromatograph equipped with a capillary column (DB-5, $60 \mathrm{~m}$, internal diameter $0.32 \mathrm{~mm}$ ) coupled to a VG70SQ magnet sector instrument (VG Analytical, Manchester, UK) running in EI+/SIR mode, low resolution. Gas chromatography injection temperature was $230^{\circ} \mathrm{C}$. The initial column temperature of $160^{\circ} \mathrm{C}$ was held for two minutes, then programmed to $300^{\circ} \mathrm{C}$ at $10^{\circ} \mathrm{C} / \mathrm{min}$ and held for five minutes. ${ }^{13} \mathrm{C}_{6}-\mathrm{HCB}, 99.9 \%$, spiked to the sample before extraction was recovered to $70 \%-90 \%$. Measurement of HCB and OCS was carried out with ${ }^{12} \mathrm{C}_{6}-\mathrm{HCB}$ and ${ }^{12} \mathrm{C}_{8}$-OCS standards. The results were adjusted for the recovery of ${ }^{13} \mathrm{C}_{6}-\mathrm{HCB}$. The detection limit of the analytical method was $0.8 \mathrm{ng} / 1$ for $\mathrm{HCB}$ and $0.6 \mathrm{ng} / 1$ for OCS. The HCB and OCS concentrations were adjusted to the lipid content of the plasma determined according to Burse et al..$^{22}$

All solvents used were distilled in glass (Burdick and Jackson, Mississauga, Ontario, Canada). Laboratory chemicals were of analytical grade. Column chromatography material (silica gel, sulphuric acid impregnated silica gel, and basic silica gel) were prepared as described by Smith et al. ${ }^{23}{ }^{12} \mathrm{C}_{6}-\mathrm{HCB}$ and ${ }^{12} \mathrm{C}_{8}-$ OCS were purchased from Referensmaterial $\mathrm{AB}$, Ulricehamn, Sweden, and ${ }^{13} \mathrm{C}_{12}-\mathrm{PCB}$ IUPAC no 101 and ${ }^{13} \mathrm{C}_{6}-\mathrm{HCB}$ were obtained from Larodan Fine Chemicals AB, Malmö, Sweden.

Several aliquots of a pooled sample of reference plasma were analysed during the period of the study. The results obtained from a series of seven separate runs had a coefficient of variation of less than $5 \%$.

\section{EXPOSURE ASSESSMENT}

From the questionnaires and from interviews with the smelters as well as figures on historical hexachloroethane consumption obtained in an earlier survey several estimates of cumulative exposure to hexachloroethane were calculated. The calculations were conducted blind from the results of the plasma analyses. The estimates were total duration of employment as a foundry worker, duration of employment as a smelter, duration of exposure to hexachloroethane while employed as a smelter, cumulative amount of hexachloroethane used at each foundry, and the consumption of hexachloro- 
Table 1 Plasma concentrations (ng/g lipid) of P-HCB and $P-O C S$ in aluminium foundry workers who use hexachloroethane for degassing and in controls

\begin{tabular}{lccl}
\hline Compound & $\begin{array}{l}\text { Exposed, } n=9 \\
\text { mean }(S D)\end{array}$ & $\begin{array}{l}\text { Controls, } n=18 \\
\text { mean (SD) }\end{array}$ & $\begin{array}{l}\text { Pvalue } \\
\text { (ANOVA) }\end{array}$ \\
\hline P-HCB & $313.1(427.5)$ & $66.9(26.7)$ & ND \\
ln P-HCB & $5.1(1.2)$ & $4.1(0.4)$ & 0.002 \\
P-OCS & $54.6(98.8)$ & $0.7(0.7)$ & ND \\
ln P-OCS & $1.2(3.3)$ & $-1.0(1.1)$ & 0.003 \\
\hline
\end{tabular}

$\mathrm{ND}=$ not done.

ethane during the last year of hexachloroethane practise. ${ }^{24}$ However, it should be noted that all participating foundries had stopped using hexachloroethane for aluminium degassing some two to four years before this investigation.

\section{STATISTICAL METHODS}

Differences between the exposed and the control workers were investigated by analysis of variance (ANOVA). In the analysis the nine triplets, each with one case and two controls, were regarded as a random factor (nine different levels) and exposure as a fixed factor (two different levels). With this formulation the ANOVA model is a generalisation of the paired $t$ test. To ensure better compliance with the assumptions of the statistical model, the normality assumption and the assumption of roughly equal variances, the calculations were performed on logarithmic values of the outcome variables. A non-parametric analysis with Quade's test ${ }^{25}$ with calculation of exact $P$ values for small samples according to Mehta and Patel ${ }^{26}$ was performed as an additional precaution.

The relation between plasma HCB (P-HCB) and plasma OCS (P-OCS)(logarithmic values) with the years of exposure to hexachloroethane was analysed by linear regression applied on the nine triplets. The dependent variable was the difference in logarithmic value between the exposed subject and the mean of the individually matched controls. The difference was regressed on the duration of exposure to hexachloroethane during employment as an aluminium smelter worker.

\section{Results}

Figure 1A shows that the P-HCB concentration varied considerably among the nine exposed subjects with the matching retained. There was no difference between exposed subjects and controls in four of the triplets whereas in the remaining five triplets this difference was clearly seen. On a group basis there was a fourfold increase of the mean P-HCB concentra-

Table 2 Serum concentrations of standard kidney, pancreas, and liver function variables in aluminium foundry workers exposed to hexachloroethane and controls

\begin{tabular}{llll}
\hline Variable in serum samples & $\begin{array}{l}\text { Exposed, } n=8 \text { mean } \\
\text { (range) }\end{array}$ & $\begin{array}{l}\text { Controls, } n=16 \text { mean } \\
\text { (range) }\end{array}$ & Reference \\
\hline S-creatinine $(\mu \mathrm{mol} / \mathrm{l})$ & $90.8(81-104)$ & $90.1(75-109)$ & $<125$ \\
S- $\alpha$-amylase $(\mu \mathrm{kat} / \mathrm{l})$ & $3.1(1.8-4.5)$ & $3.5(1.1-6.7)$ & $1.4-6.0$ \\
S-bilirubin $(\mu \mathrm{mol} / \mathrm{l})$ & $8.3(2-14)$ & $8.9(4-16)$ & $<25$ \\
S-ALP $(\mu \mathrm{kat} / \mathrm{l})$ & $2.8(1.9-3.7)$ & $2.8(1.4-4.8)$ & $0.8-4.6$ \\
S-ASAT $(\mu \mathrm{kat} / \mathrm{l})$ & $0.4(0.4-0.5)$ & $0.4(0.3-1.0)$ & $<0.70$ \\
S-ALAT $(\mu \mathrm{kat} / \mathrm{l})$ & $0.4(0.1-0.9)$ & $0.5(0.2-1.7)$ & $<0.70$ \\
S-GT $(\mu \mathrm{kat} / \mathrm{l})$ & $0.5(0.2-1.5)$ & $0.4(0.2-0.8)$ & $<1.0$ \\
S-LD $(\mu \mathrm{kat} / \mathrm{l})$ & $6.1(5.2-7.6)$ & $5.7(4.9-6.8)$ & $<8.5$ \\
\hline
\end{tabular}

S-ALP=alkaline phosphatase; S-ALAT=alanine aminotransferase; S-ASAT=aspartate aminotransferase; $\mathrm{S}-\mathrm{GT}=\gamma$-glutamyltransferase; $\mathrm{S}-\mathrm{LD}=$ lactate dehydrogenase. tion among the exposed compared with the control subjects (table 1). The P-HCB values were considered to be roughly log normally distributed and after $\log$ transformation the difference between the exposed subjects and the controls was significant $(P=0.002)$. For OCS, the difference in P-OCS between exposed subjects and controls (triplets retained) was similar (fig 1B). The mean for the exposed group was more than 75 times higher than that of the controls $(\mathrm{P}=0.003$ after log transformation) (table 1).

The non-parametric analysis gave similar results although with higher $P$ values $(P=0.030$ and $P=0.046$, respectively).

The highest correlation between the difference in In P-HCB for the foundry workers and their matched controls and the various estimates of cumulative exposure was obtained for the duration of exposure to hexachloroethane in work as an aluminium smelter $(r=0.80$; fig 2A). A slightly higher correlation $(r=0.91)$ was found for $\ln$ P-OCS (fig 2B). For the entire study group there was an almost perfect linear relation between In P-HCB and In P-OCS $(r=0.93)$.

In the analysis of standard variables of inner organ function the data from serum samples of one of the nine triplets were missing. Table 2 shows the mean values and the minimum and maximum values, separately for the exposed group and the controls. ANOVA modelling showed no significant differences between the two groups.

\section{Discussion}

Aluminium degassing with hexachloroethane may be one of the most ubiquitous and important sources of HCB and OCS to the general environment known so far, and the emissions of HCB in the United Kingdom alone have been estimated to reach some $3000 \mathrm{~kg}$ annually in the early $1990 \mathrm{~s}^{8}$ In this study of exposed aluminium foundry workers the results indicate that aluminium degassing with hexachloroethane may also entail a considerable increase in the body burden of these biologically stable and toxic organochlorine compounds. These findings were obtained although some of the exposed subjects had only limited experience of this particular process, and a lag time of up to four years from the end of exposure to blood sampling was inevitable, suggesting that even higher concentrations of HCB and OCS would have been found given a more recent exposure. The half lives in humans for the organochlorine compounds of interest are probably very long albeit not very well known ${ }^{27}$ and backward extrapolation is a delicate task.

The selection of foundries for this study was based on information about the use of hexachloroethane for aluminium degassing obtained in a previous survey of most Swedish aluminium foundries-that is, the use of hexachloroethane had been positively identified and grossly measured by company officials. Obviously, details about the background of the workforce at each company had to be left to the judgement of the foundry officials who were asked to identify their smelters with the 

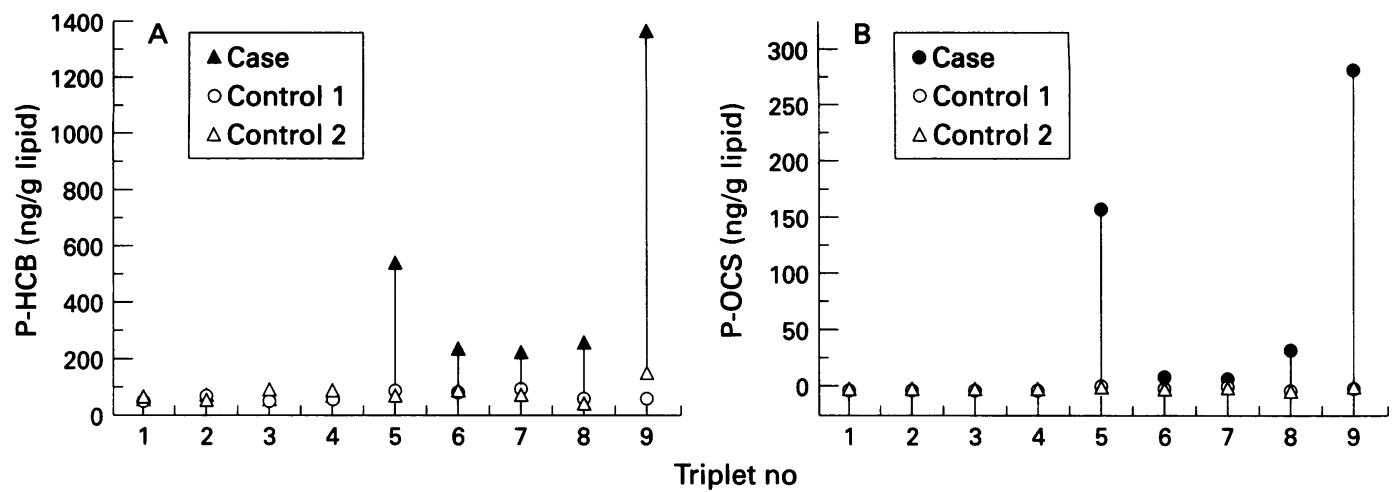

Figure 1 Concentrations of (A) P-HCB and (B) P-OCS in aluminium foundry workers exposed to hexachloroethane for degassing (cases) and in controls. Matching retained and triplets sorted according to order of duration of exposure of the cases.

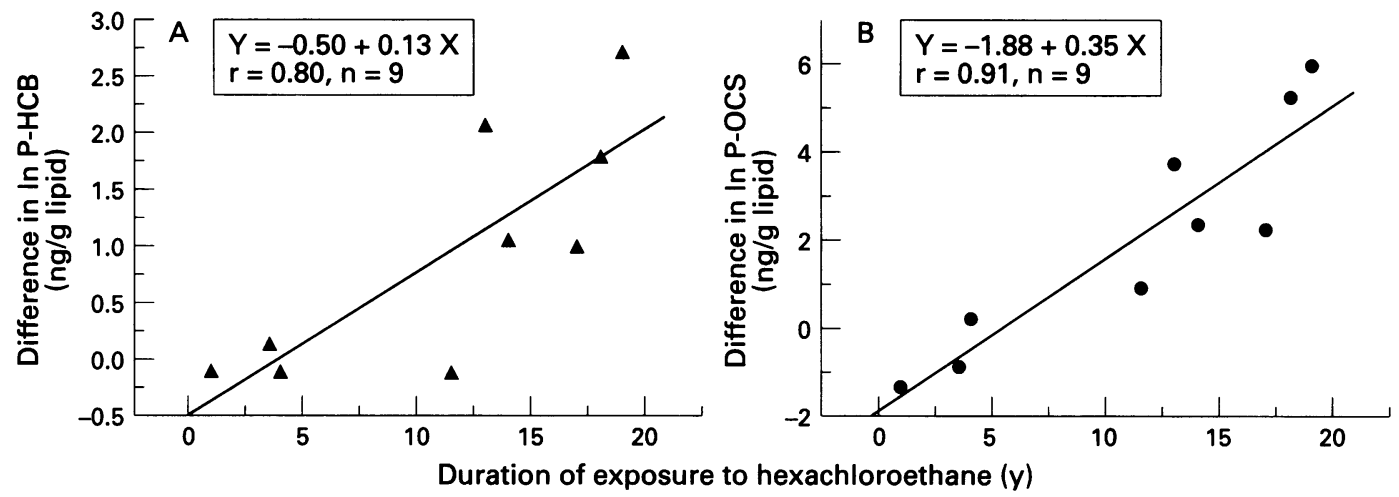

Figure 2 Difference in (A) In P-HCB and (B) In P-OCS in aluminium foundry workers and the mean of their matched controls regressed on cumulative duration of exposure to hexachloroethane.

longest experience of hexachloroethane. To balance company influence, most controls were selected independently by local occupational health nurses.

The assessment of exposure was hampered by the lack of adequate measurements of $\mathrm{HCB}$ or other organochlorine compounds originating from aluminium degassing with hexachloroethane before the end of exposure. Specifically, there were no longitudinal exposure data. In an orientating investigation at one of the foundries included in the present study some years earlier, a time weighted average HCB concentration of $0.010 \mathrm{mg} / \mathrm{m}^{3}$ was obtained, whereas area measurements varied widely. Figure 2A+B shows that the $\mathrm{P}-\mathrm{HCB}$ and $P$-OCS concentrations increase exponentially with duration of exposure to HCE as the logarithmic values of these variables showed a linear increase with duration of exposure. This could possibly be explained by a combination of higher exposures in the past and a gradual decrease in exposure before the definite end of HCE degassing. Given the deficit of good exposure data, this possibility remains speculative. Indirect evidence of exposure such as the consumption of HCE over time were crude and proved not to be useful. Clearly, proper exposure measurements should be conducted where this degassing technique still can be identified.

The background concentrations of $\mathrm{HCB}$ and OCS were homogenous among the controls. To the best of our knowledge, there are no published data on the historical or contempo- rary plasma HCB or OCS concentrations in Swedish men, although serial analyses of HCB in human breast milk samples from the Stockholm area indicate a declining trend since the early 1970 s. ${ }^{28}$ However, data from two unpublished studies of municipal waste and hazardous waste workers in central Sweden (Seldén et al 1994, Seldén et al 1996) showed mean P-HCB concentrations of 25-35 $\mathrm{ng} / \mathrm{g}$ lipid among their controls $(n=69)$, analysed with the same technique and at the same laboratory as in the present study. These mean concentrations of P-HCB are about half as high as the controls of the present study. The discrepancy among the controls of these different studies are not likely to be due to geographical or social differences, as they were all blue collar workers from central and south eastern Sweden. Of the controls, $89 \%$ in the present study were recruited from the same companies as the exposed workers (cases). Although they did not work in the same buildings as the corresponding case they may have experienced a mutual indirect low level environmental exposure (sharing dressing rooms, canteens, etc) to both HCB and OCS, which may have introduced some negative confounding.

Deposited primarily in lipid rich tissues, HCB is slowly metabolised, probably in the liver, mainly to pentachlorophenol and pentachlorobenzene and excreted into the feces and the urine. ${ }^{16}$ However, the toxicity of HCB in both experimental animals and humans is considered to be determined largely by more reactive intermediates formed by complex 
metabolic pathways. ${ }^{29}$ The metabolism of OCS is less well characterised, specifically in humans. In rats, however, pentachlorophenyl dichloroacetic acid has been identified as the main metabolite, ${ }^{30}$ whereas the half life of OCS in rainbow trout liver, as estimated from preliminary data, was nearly twice as long as for $\mathrm{HCB} .^{31}$

With the standard variables for hepatotoxicity used in the analysis of the serum samples no significant difference was found between the exposed foundry workers and the controls. For the other routine analyses both groups had similar and normal values. The limited size of the study population and the historical exposure of interest preclude general conclusions but within the scope of the present study no evidence of subclinical organ toxicity was found. Sweden has no occupational exposure limits or biological exposure indices for HCB or OCS. However, in Germany a BAT (Biologischer Arbeitsstoff-Toleranz-Wert) value for HCB in plasma or serum of $150 \mu \mathrm{g} / 1$ (about $145 \mathrm{ppb}$ ) has been established. ${ }^{32}$ Even the highest P-HCB value in the present study (8.6 $\mathrm{ppb}$, unadjusted for lipid content) was well within the German BAT value and the absence of systemic effects may thus be regarded as consistent with this standard.

In the statistical analysis the matching of exposed cases and controls was retained. This should increase the power of the test. However, the data set was small and the distributional properties of the main outcome variables, P-HCB and P-OCS, were far from a normal distribution. With logarithmic transformation a better, but still not perfect, compliance with the normality assumption was accomplished. An additional non-parametric method for which no specific distributional assumptions had to be fulfilled gave similar results.

Exposed subjects and controls differed in smoking habits: $78 \%$ of the exposed group were smokers or ex-smokers versus $50 \%$ for the controls. However, tobacco smoke is not reported to be a major source of organochlorine compounds ${ }^{33}$ and the differences found in the present study are not likely to be explained by differences in smoking behaviour. Moreover, background exposure to most stable organochlorine contaminants is thought to be alimentary ${ }^{34} 35$ and the matching of controls by socioeconomic status and residency was considered to be sufficient proxies for habits in food consumption given the exploratory nature of the study. However, as no detailed food history was collected, the possibility of systematic differences between the groups cannot be excluded but it seems unlikely.

The increased concentrations of HCB and OCS still found in the plasma of aluminium foundry smelters years after the end of exposure and the relatively simple and cheap analytical method applied here indicate that both substances could be succesfully used for biological monitoring in settings where hexachloroethane is used for aluminium degassing. The background concentrations of $\mathrm{HCB}$, however, are higher than for OCS and the contrast between exposed cases and controls was more obvious for OCS suggesting that it would be the primary choice. However, steps have already been taken by the European Union to phase out HCE as a light metal degassing agent within the next few years, ${ }^{2036}$ mainly for environmental reasons, but biological monitoring of organochlorine compounds in aluminium foundry workers may still be useful elsewhere.

In view of its potential human toxicity, additional attempts should be made to document this occupational and environmental exposure to biologically stable and toxic organochlorine compounds. In Scandinavia this seems no longer feasible but circumstantial evidence indicates that hexachloroethane is still used for degassing elsewhere within the European Union and in other parts of the world. The chemical also remains as an additive to so-called grain refining reagents for light metal castings. ${ }^{13}$

It is concluded that aluminium degassing with hexachloroethane may increase the body burden of HCB and OCS and possibly other organochlorine compounds, but additional studies in larger and more recently exposed populations should be undertaken before an adequate asessment of risk to human health can be made.

This study was made possible only by the generous cooperation of nurses from several occupational health centres in central and south eastern Sweden, the companies and workers involved, and a grant from the Research Committee of the Örebro County Council (no 632-92). Ing-Liss Bryngelsson assisted in data management. We also thank Professor Olav Axelson for comments on the manuscript.

1 Boddey RF. The use of chemicals in the modern foundry Ann Occup Hyg 1967;10:231-9.

2 Kanicki DP, Rasmussen WM. Processing molten aluminum-part 2: cleaning up your metal. Modern Casting 1990;80:55-8.

3 Bunbury FM. Foundry Services Limited-fifty years of succesful innovation. Foundry Trade fournal 1982;153:75-111.

4 Harriss RJ, Cesana A. Aluminium treatment technology of the future-the flux injection process. British Foundryman 1987;80:434-40.

5 Presche P. Behandlung von Aluminiumschmelzen mit Gasgemischen (treatment of aluminium melts with gas gemischen (treatment of aluminium melts with
mixtures). Aluminium 1972;48:677-9. (In German.)

6 Maier K. Die Entstehung von Hexachlorbenzol bei der Schmelzebehandlung von Aluminiumlegierungen (Formation of hexachlorobenzol in the treatment of aluminium alloy melts). Giesserei 1988;75:149-52. (In German.)

7 Månsson L, Seldén A. Emission of organochlorine compounds from an aluminium remelting plant. In: Corbella J, ed. Proceedings from (Libro de actas) las. Fornadas nacionales sobre hexaclorobenceno; 1988 May 23-24. Barcelona: Publicaciones del Seminario Pere Mata de la Universidad de Barcelona, 1990:73-5. (Publ No 41.)

8 Westberg HB, Seldén AI, Bellander T. Emissions of some organochlorine compounds in experimental aluminium degassing with hexachloroethane. Appl Occup Environ Hyg 1997;12:178-83.

9 Ockner RK, Schmid R. Acquired porphyria in man and rat due to hexachlorobenzene intoxication. Nature 1961;189: 499.

10 Stonard MD. Experimental hepatic porphyria induced by hexachlorobenzene as a model for human symptomatic porphyria. Br $\mathcal{F}$ Haematol 1974;27:617-25.

11 Strik JJTWA, Koeman JH. Porphyrinogenic action of hexachlorobenzene and octachlorostyrene. In: Doss $\mathrm{M}$, ed. Porphyrins in human disease. Basel: S Karger, 1976:418-23.

12 Smith AG, Francis JE, Bird I. Distinction between octachlorostyrene and hexachlorobenzene in their potentials to rostyrene and hexachlorobenzene in their potentials to induce ethoxyphenoxazone deethylase and cause porph

13 Schmid R. Cutaneous porphyria in Turkey. N Engl f Med 1960;263:397-8.

14 Cam C, Nigogosyan G. Acquired toxic porphyria cutanea tarda due to hexachlorobenzene. $¥ A M A$ 1963;183:88-91.

15 Gocmen A, Peters HA, Cripps DJ, Bryan GT, Morris CR. Hexachlorobenzene episode in Turkey. Biomed Environ $S c i$ 1989;2:36-43.

16 American Conference of Governmental Industrial Hygienists. Notice of intended change-hexachlorobenzene. Appl Occup Environ Hyg 1992;7:778-85. 
17 International Agency for Research on Cancer. Hexachlorobenzene. Overall evaluations of carcinogenicity: an updating robenzene. Overall evaluations of carcinogenicity: an updating
of $I A R C$ monographs. Vol 1-42. Lyon: International Agency of LARC monographs. Vol 1-42. Lyon: Internation

18 Seldén A, Jacobson G, Berg P, Axelson O. Hepatocellular carcinoma and exposure to hexachlorobenzene: a case report. Br F Ind Med 1989;46:138-40.

19 Grimalt JO, Sunyer J, Moreno V, Amaral OC, Sala M, Rosell $A$, et al. Risk excess of soft-tissue sarcoma and thyroid can cer in a community exposed to airborne organochlorinated compound mixtures with a high hexachlorobenzen content. Int $\mathcal{Y}$ Cancer 1994;56:200-3.

20 Anonymous. Oslo/Paris Commission bans hexachloroethane. European Chemical News 5 July 1993;26.

21 Ydreborg B. Questionnaire-based database on occupation and health status. Inf Serv Use 1990;10:47-51.

22 Burse VW, Head SL, Korver MP, McClure PC, Donahue JF, Needham LL. Determination of selected organochlorine pesticides and polychlorinated biphenyls in human rine pesticides and polychlorinated bipl

23 Smith LM, Stalling DL, Johnson JL. Determination of partper-trillion levels of polychlorinated dibenzofurans and dioxins in environmental samples. Anal Chem 1984;56: 1830-42.

24 Checkoway $\mathrm{H}$. Methods of treatment of exposure data in occupational epidemiology. Med Lav 1986;77:48-73.

25 Conover WJ. Practical non-parametric statistics. 2nd ed. New York: John Wiley, 1980.

26 Mehta C, Patel N. StatXact 3 for Windows. Statistical software for exact non-parametric inference. User manual. Cambridge, MA: Cytel Software Corporation, 1995.

27 Yesair DW, Feder PI, Chin AE, Naber SJ, Kuiper-Goodman T, Siegel Scott C, Robinson PE. Development, evaluation and use of a pharmacokinetic model for hexachlorobenand use of a pharmacokinetic model for hexachlorobenzene. In: Morris CR, Cabral JRP, eds. Hexachlorobenzene: Proceedings of an International Symposium; 24-8 Jun 1985; Lyon.Lyon: International Agency for Research
1986:297-318. (IARC Scientific Publ No 77.)
28 Norén K. Studies on organochlorine contaminants in human milk [dissertation]. Stockholm: Karolinska Institutet, 1987 29-30.

29 den Besten C, Brouwer A, Rietjens IMCM, van Bladeren PJ. Biotransformation and toxicity of halogenated benzenes. Hum Exp Toxicol 1994;13:866-75.

30 Chu I, Villeneuve DC, Secours V, Benoit FM, Viau A. The tissue distribution, metabolism and excretion of octachlorostyrene in the rat. Drug Metab Dispos 1982;10:632-5.

31 Tarkpea M, Hagen I, Carlberg GE, Kolsaker P, Storflor H. Mutagenicity, acute toxicity, and bioaccumulation of six chlorinated styrenes. Bull Environ Contam Toxicol 1985;35 525-30.

32 Deutsche Forschungsgemeinschaft. List of $M A K$ and $B A T$ values 1995. Weinheim: VCH Verlagsgesellschaft, 1995. (Report No 31.)

33 International Agency for Research on Cancer. Tobacco smoking. IARC monographs on the evaluation of the carcinogenic risk of chemicals to humans. Lyon: IARC, 1986;38:83 126.

34 Ahlborg UG, Håkansson H, Waern F, Hanberg A. Nordisk dioxinriskbedömning. Rapport från en nordisk expertgrupp Nordic dioxin risk assessment. Report from a Nordic expert group). Copenhagen: Nordiska Ministerrådet, Nord 1988 49. (In Swedish, English summary.)

35 World Health Organization. Polychlorinated biphenyls and terphenyls (2nd ed). Environmental Health Criteria 140 Geneva: World Health Organization, 1993:188

36 European Commission. Proposal for a European Parliamen and Council Directive amending for the 16th time Council Directive 76/769/EEC on the approximation of the laws, regulations and administrative provisions of the Member regulations and administrative provisions of the Member States relating to restrictions on the marketing and use of
certain dangerous substances and preparations (94/C 382/ 07). Official fournal of the European Commission 1994; 37(No C 382):35-6. 